\title{
REFLEXÕES SOBRE DUAS EXPERIÊNCIAS DE INTEGRAÇÃO DAS TDIC AO CURRÍCULO ESCOLAR
}

\author{
Cristiane A. Neri FIDELIX \\ (Faculdade Sumaré) \\ profcrisfidelix@hotmail.com \\ Susana Ester KRUGER-DISSENHA \\ (Pontifícia Universidade Católica de São Paulo) \\ sekruger@uol.com.br
}

Resumo: Este artigo apresenta duas experiências de integração das Tecnologias Digitais de Informação e Comunicação (TDIC) ao currículo escolar na construção de diferentes tipos de narrativas digitais. A primeira relata uma oficina sobre criação de livros digitais, para professores do Ensino Fundamental I de uma escola pública municipal, com trabalhos construídos por eles e seus alunos em sala de aula, em aulas da área de português e literatura, como parte do Projeto UCA. A segunda relata um projeto de ensino na disciplina de Tecnologia Educacional para alunos de curso de pedagogia onde foi desenvolvida uma fotonovela, a partir dos princípios da Educomunicação. A partir das experiências aqui descritas, refletimos sobre algumas razões que, em nosso entender, fundamentam e justificam a integração das TDIC em contexto escolar, propiciando a utilização, integração e potencialização das TDIC para contribuírem efetivamente na busca da qualidade educativa das atividades pedagógicas.

Palavras-chave: TDIC. Livros Digitais. Projeto UCA. Fotonovelas. Narrativas Digitais.

Abstract: This article presents two experiments of Information and Communication Technologies (ICT) integration to the school curriculum in the construction of different types of digital storytelling. The first reports a workshop on creating digital books for the elementary school teachers, as well as the subsequent work done by teachers with their students involving Portuguese and children's literature, as part of the UCA Project. The second one relates a project developed in the subject Educational Technology for undergraduate students of pedagogy, where we developed a Fotonovela, based on the principles of Educomunication. Through the experiments described here, we reflect on some reasons that, in our view, underlie and justify the integration of ICT in the school context, allowing the use, integration and empowerment of ICT to contribute effectively in the pursuit of educational quality of pedagogical activities.

Keywords: ICT. Digital e-books. UCA Project. Photo novels. Digital storytelling. 


\section{Introdução}

Este texto apresenta e analisa duas experiências realizadas com diferentes públicos-alvo na produção de narrativas digitais ${ }^{1}$. Elas podem ser relatadas de diferentes maneiras; "no entanto, as narrativas vão além das histórias. O fenômeno em si constitui a história, enquanto o método que a descreve e a investiga se concretiza em uma narrativa" (GALVÃO, 2005). Mesmo utilizando como referência o conceito de "narrativas digitais", cabe ressaltar que o foco deste artigo não reside no estudo dos gêneros discursivos

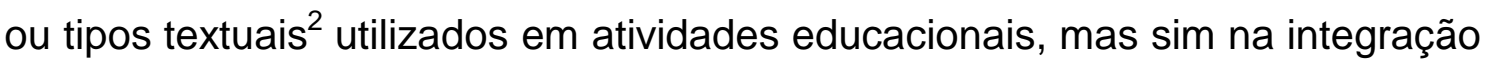
curricular possibilitada pelas TDIC (Tecnologias Digitais de Informação e Comunicação) durante estas atividades.

Com a evolução da tecnologia surgiram várias ferramentas capazes de fazer animações em histórias e personagens. Segundo Bottentuit Junior (2011), estes recursos permitem que elas saltem do mundo imaginário para um mundo real, colorido e animado. Há pouco tempo as tecnologias eram utilizadas mais especificamente por profissionais da área, mas aos poucos também nas escolas têm sido utilizados aplicativos da geração Web 2.0, que permitem a criação de narrativas digitais, de forma mais facilitada com recursos como 0 Flash para animação; o MovieMaker para edição de imagem e vídeo; o PowerPoint ou as ferramentas para criação de Blog. De acordo com Carvalho (2008),

a construção e produção de narrativas digitais se constituem num processo de produção textual que assume o carácter contemporâneo dos recursos audiovisuais e tecnológicos capazes de modernizar 'o contar histórias', tornandose uma ferramenta pedagógica eficiente e motivadora ao aluno, ao mesmo tempo em que agrega à prática. (p.87).

Segundo Paiva (2009, s/p), "com o advento das tecnologias

\footnotetext{
${ }^{1}$ Este artigo resulta, em parte, de um estudo realizado para a disciplina Currículo, Aprendizagem e Narrativas Digitais (2o sem/2014) do Programa de Pós-graduação em Educação: Currículo da PUC-SP, ministrado pela Dra. Maria Elizabeth B. de Almeida em colaboração com o Dr. José A. Valente. As autoras agradecem aos professores pelas sugestões oferecidas, e também à colega Lucia Amaral.

2 As autoras concordam com as observações e reflexões sobre este tema apontadas por Baldo (2004), que por sua vez se apoia em Bakhtin (1992), Bonini (2001), Hasan (1978), Marcuschi (1996), Swales (1990), entre outros.
} 
computadorizadas novos formatos de produção de texto emergem nas práticas sociais da linguagem, dentre elas a narrativa multimodal e multimídia". Portanto, são múltiplas e diversas as atividades em que as TDIC podem ser empregadas em contexto pedagógico, desde a utilização dos aplicativos básicos do computador como o uso do processador de texto, folhas de cálculo, programas para criação de apresentações eletrônicas e desenhos, até aos recursos mais avançados disponibilizados através das facilidades acrescidas da Internet, como o chat, fórum, portais, plataformas de aprendizagem.

Por outro lado, a falta de conhecimento de muitos professores sobre as tecnologias e suas potencialidades torna-se um fator de resistência ao processo de inovação. Segundo Silva (1997) as mudanças precisam ocorrer, mais cedo ou mais tarde, sob o risco da escola se afastar perigosamente da sociedade. Para que isto não aconteça, são necessários níveis mais elevados de qualificação e de conhecimentos, tanto no domínio das tecnologias quando de seu uso pedagógico, visando à sua adequação e integração aos objetivos curriculares da escola. O novo perfil do professor é de planificador e utilizador crítico e reflexivo dos recursos tecnológicos na sala de aula (COUTINHO, 2010). Por estes motivos, são importantes ações de formação inicial e continuada de professores para o uso pedagógico crítico e reflexivo das tecnologias em sala de aula, para que vivenciem sua utilização e reflitam sobre as possibilidades de recontextualização em suas aulas. A familiarização com a tecnologia e suas possibilidades didáticas e pedagógicas levará à maior facilidade em planejar, desenvolver e reavaliar as atividades educacionais realizadas com estes recursos. Ao mesmo tempo, é importante atentar para que o foco das atividades não seja nas TDIC e sim na produção do conhecimento propriamente dito:

Em geral, o fato de o aprendiz conseguir produzir a narrativa (ter o produto), ou de ser capaz de usar os recursos tecnológicos (ter o domínio da tecnologia), rouba a cena e acaba sendo mais importante do que o processo de produção, de construção dos conhecimentos relativos aos conteúdos utilizados. (ALMEIDA; VALENTE, 2012, p.59)

É neste contexto de formação que foram realizadas as vivências aqui descritas. Elas ocorreram em dois diferentes contextos: na formação 
continuada de professores em atuação, em uma escola pública municipal (oficina de livro digital) e na formação inicial em um curso de pedagogia de uma faculdade particular (oficina de fotonovela).

\section{Oficina de livro digital}

A primeira atividade aqui relatada explorou o conceito de livros digitais. $O$ conceito técnico deste tipo de publicação foi encontrado em Dourado e Oddone (2012), que diferenciam livro digital (acesso por diferentes mídias), livro eletrônico (para mídias específicas) e misto (ou talvez, livro eletrônico digital):

[...] o livro digital caracteriza-se pela codificação em dígitos binários e pelo acesso através de um sistema computacional. Já o livro eletrônico é considerado aquele que só pode ser acessado e decodificado através de um equipamento eletrônico, como seria o caso de um áudio-livro gravado em fita cassete. Como consequência, "todo documento digital é eletrônico, mas nem todo documento eletrônico é digital" (CONARQ, 2010). Por extensão, todo livro que depende de um equipamento eletrônico específico - como são muitos dos e-readers e tablets - para ser acessado e lido, também é considerado um livro eletrônico. (DOURADO; ODDONE, 2012, p.133).

O edital do Programa Nacional do Livro Didático 2015 para o ensino médio inclui normas específicas para a confecção de material digital para as escolas. O edital aceita dois tipos de obras didáticas, a primeira sendo "obra multimídia composta de livros digitais e livros impressos" e a segunda como "obra impressa composta de livros impressos e PDF" (Item 3, p.01). Posteriormente especifica:

4.2.2. Os livros digitais deverão apresentar o conteúdo dos livros impressos correspondentes integrados a objetos educacionais digitais. 4.2.3 Entende-se por objetos educacionais vídeos, imagens áudios, textos, gráficos, tabelas, tutoriais, aplicações, mapas, jogos educacionais, animações, infográficos, páginas web e outros elementos (PNLD 2015, p.3).

Editais como este, de impacto nacional, demonstram a crescente tendência de inclusão das obras digitais no ensino básico. Um outro incentivo para o uso das TDIC nas escolas pode ser visto, por exemplo, no Projeto UCA Um Computador por Aluno (MEC/SEB - Ministério da Educação/Secretaria da 
Educação). A fase Pré-Piloto (2005) ocorreu em cinco escolas públicas, em diferentes estados brasileiros, tendo sido coordenada pela PUC-SP em parceria com outras universidades. Em 2010, o Projeto Piloto foi realizado em aproximadamente 300 (trezentas) escolas públicas, com netbooks para uso individual por alunos e professores, e formação dos professores e gestores. $\mathrm{Na}$ terceira fase, o Programa UCA, fornece apoio financeiro parcial às prefeituras para que adquiram o netbook educacional, tendo sido regulamentado pela Lei 12.715 de 17/09/2012.

\subsection{Oficina com professores}

A oficina aqui relatada foi realizada no âmbito do Projeto UCA e de um pós-doutorado em andamento ${ }^{3}$, em uma escola no interior de São Paulo no mês de agosto de 2013. Uma turma participou no período da manhã e outra no período da tarde, no Horário de Trabalho Pedagógico Coletivo (HTPC) dos professores, por aproximadamente duas horas em cada período. Atenderam em cada período em torno de oito professores do Fundamental I - do $1^{\circ}$ ao $5^{\circ}$ ano, e o coordenador pedagógico. A oficina ${ }^{4}$ utilizou e incluiu a criação de slides no software PowerPoint (possível também em seu equivalente no Linux/Ubuntuca, o KPresenter), e então a sua disponibilização no site de publicações de livros eletrônicos ISSUU (www.issuu.com). As adaptações incluíram principalmente telas com definições e orientações sobre "livro digital", cuidados com direitos autorais e novos recursos de acesso ao ISSU através do Facebook. Esta mesma oficina foi ministrada em outras escolas integrantes do Projeto UCA, como parte da Formação Continuada em desenvolvimento em 2013.

Os professores quiseram explorar o recurso enquanto o roteiro de confecção do "livro digital" era explicado, e por isso utilizaram simultaneamente os computadores. No caso dessa oficina, eles se organizaram em grupos de quatro pessoas - portanto, dois projetos em cada turno, totalizando quatro

\footnotetext{
${ }^{3}$ Edital 001/2010 MEC/CAPES e MCT/CNPq/FINEP (ALMEIDA, 2010). Projeto em andamento: Kruger-Dissenha (2012).

${ }^{4}$ Criação de Silvana Lemos, adaptação de Susana E. Kruger-Dissenha.
} 
livros digitais, conforme mostra a Figura 1: Manhã: Noite do pijama (releitura das professoras Crislaine, Myriam e Taciana e da estagiária Suellen, baseada em Viviana, a Rainha do Pijama, de Steve Webb ; Sem pé nem cabeça, de Elias José (releitura de Sara, Aldo, Rafaela e Paula). Tarde: O macaco e a meia - baseado em $O$ macaco e a Mola, de Sonia Junqueira (releitura das professoras Adriana, Jussara e Silvana e do estagiário Wesley); A festa no céu - conto popular (releitura de Ana Lidia, Elaine, Elisangela e Maria Elizete).
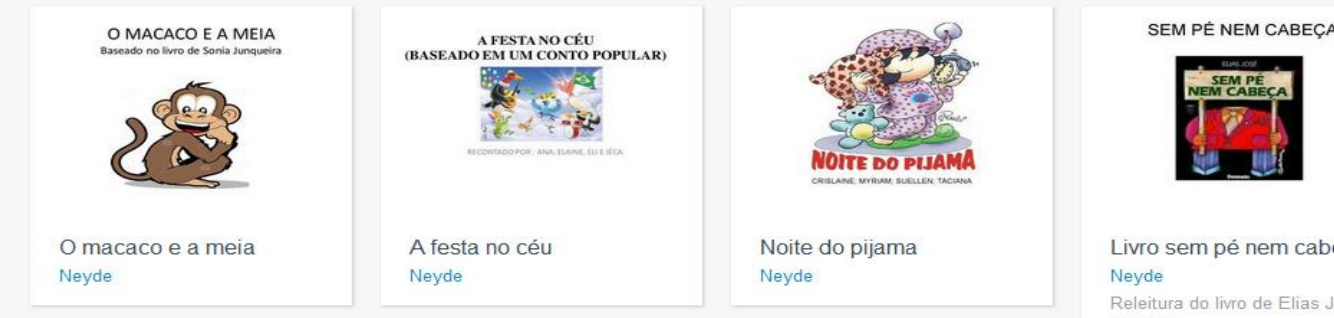

Figura 1: Printscreen dos livros digitais criados pelos professores das oficinas (vide www.issuu.com/neydemarao)

Conforme pode ser visto, três grupos utilizaram como referência os livros disponíveis para as crianças na escola, e um deles optou por escrever um conto popular. Todos observaram a necessidade de parafrasear, resumir ou recriar o livro original, mencionando a fonte original e, ao final, incluir um índice com os links das fontes das imagens que escolheram para ilustrar o texto.

Aos professores de ambos os períodos, foi sugerido que trabalhassem nos laptops UCA, porém preferiram utilizar os computadores do laboratório de informática da escola, onde estava sendo realizado o HTPC, por terem mais recursos e pela velocidade em que poderiam pesquisar as imagens na internet e criar a apresentação em PowerPoint. O apoio técnico dos estagiários e a colaboração entre pares foram relevantes para que os professores pudessem elaborar esse material, pois alguns tinham dúvidas sobre o uso do PowerPoint, sobre a diminuição do tamanho dos links das imagens para citação nos créditos do livro digital, etc. Ao mesmo tempo em que alguns tiveram essas dúvidas, outros demonstraram interesse em criar livros com figuras animadas, não apenas um pdf estático, não interativo, embora não fosse possível acrescentar tais características de interação e animação aos slides criados no PowerPoint 
devido ao tipo de arquivo a ser criado e disponibilizado no ISSUU (pdf). Ademais, nos links indicados na oficina e na continuidade da formação no EProinfo, o assunto poderia ser aprofundado pelo conhecimento de outros recursos.

Para compartilhar as produções, a estagiária da manhã criou uma conta no ISSUU para a escola, que também foi acessada pelos participantes do turno da tarde e foi posteriormente ampliada com publicações dos trabalhos dos alunos. Ao final da oficina, os participantes disponibilizaram suas versões em caráter preliminar, visto que pretendiam aperfeiçoá-las quanto ao texto e adicionar outras fontes das imagens.

\subsection{Trabalhos dos professores em sala de aula}

Depois da oficina, três professoras criaram livros digitais com seus alunos, como pode ser visto na Figura 2: A borboleta que perdeu as manchinhas (profa. Myriam e prof. Wesley, 3a série, baseado no livro $A$ joaninha que perdeu as pintinhas de Ducarmo Paes, Os três ratinhos (profa. Monica, baseado no livro Os três jacarezinhos de Helen Katteman), A enchente (profa. Silvana e prof. Wesley, $4^{a}$ série, baseado no livro $O$ toró de Regina Aparecida Siguemoto) ${ }^{5}$ :
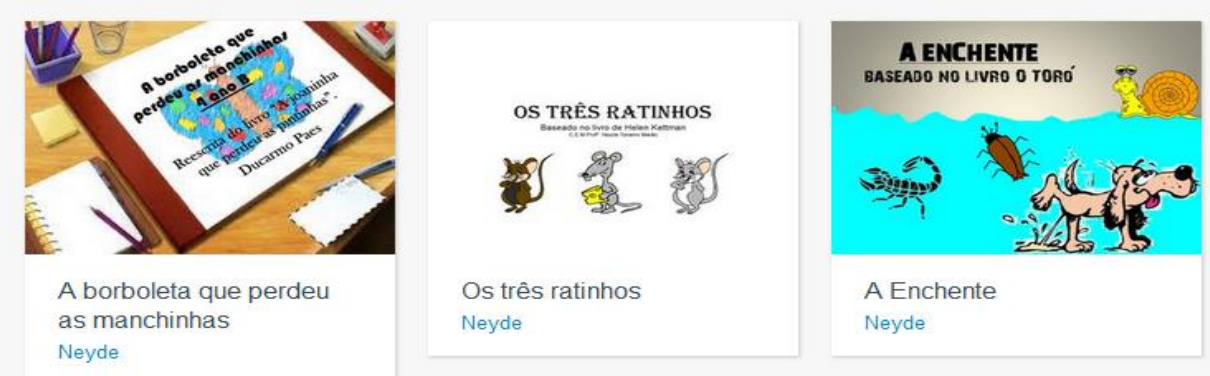

Figura 2: Printscreen dos livros digitais criados pelos alunos dos professores das oficinas (vide www.issuu.com/neydemarao)

De modo geral, as professoras seguiram a sequência de atividades proposta na oficina que vivenciaram e a realizaram em aproximadamente de três a cinco aulas. Primeiro, os professores leram o livro original junto com os

\footnotetext{
${ }^{5}$ Outros professores relataram que também criaram livros digitais com seus alunos, porém não recebemos seu material em tempo hábil para inclusão neste artigo.
} 
alunos, depois os alunos recontaram o texto da história (criando sua própria versão), procurando na internet imagens apropriadas para cada trecho, e por fim elaboraram os slides juntando texto e imagens. Os laptops UCA foram utilizados por duas professoras em conjunto com a lousa digital da escola recurso este que facilitou a visualização do projeto em andamento ou concluído; outra utilizou apenas a lousa digital. Em todos os casos, a edição final foi realizada pelo professor Wesley (auxiliar de TIC da escola), que também publicou as produções no ISSUU, utilizando para tanto os computadores do laboratório de informática da escola. A seguir o relato detalhado de uma professora:

\begin{abstract}
Conversei com meus alunos sobre a oficina que tínhamos feito com a [pesquisadora da PUC-SP] e com a ajuda do Wesley mostrei na lousa digital o livrinho que as professoras fizeram. Os alunos gostaram muito, nisso, já propus que fizéssemos um livrinho da classe fazendo uso da lousa digital. Expliquei que para isso escolheríamos um livrinho para fazer como que uma reescrita, só que diferente das reescritas que estamos acostumados, pois poderíamos mudar a história, pegando apenas a ideia principal. Eu já havia separado alguns livrinhos para ler para os alunos e para que eles escolhessem um para começarmos o nosso livro digital. Após a escolha, li novamente a história escolhida e começamos nossa história tendo o professor Wesley como nosso escriba. Primeiro focamos em escrever a história. $\mathrm{Na}$ escolha da personagem principal os alunos deram várias ideias até que a maioria escolheu a borboleta, logo em seguida pensamos no título. Todo o tempo eu e o professor Wesley buscávamos a participação das crianças de modo que fossemos avançando no texto, fazendo perguntas sobre o que escrever, como escrever, fazendo questionamentos, levando as crianças a participarem, refletindo sobre a construção da história e também da escrita correta. Foram usadas três aulas para a produção escrita. $\mathrm{Na}$ ilustração levamos duas aulas e todos os alunos puderam participar desenhando ou pintando na lousa digital, e opinando sobre a melhor maneira de expressar o texto escrito. (Professora MDP)
\end{abstract}

Em um questionário ministrado por e-mail após a oficina, perguntamos às professoras sobre a reação dos alunos: o que eles gostaram mais, gostaram menos, o que acharam fácil ou tiveram dificuldade, e duas professoras responderam com ênfases diferentes. Uma apontou a colaboração entre os alunos durante a realização da atividade, o que minimizou as dificuldades; a outra ressaltou o desafio de trabalhar com a rima enquanto conteúdo de língua portuguesa. 
Os alunos gostaram muito do livrinho da professora Silvana ${ }^{6}$ e do livrinho das professoras, foi um incentivo para fazermos o nosso próprio livrinho. Quanto ao que eles acharam difícil, na verdade não deu para eles sentirem muita dificuldade. Porque sendo um trabalho em grupo quando um não sabia, outros alunos vinham com várias ideias e o embaraço de um ou outro nem era notado, vários alunos queriam participar dando ideias que vão sendo aprimoradas pela participação de todos. Se tivéssemos feito individual tenho certeza que apareceria muitas dificuldades, mas como só trabalhamos na lousa em grupo, foi bem tranquilo. (Profa. MDP)

Eles gostaram mais de escolher as imagens e os personagens que fariam parte da história. Tiveram maior dificuldade em utilizar rimas, pois o livro é composto por rimas. (Profa. SGG).

Ambos os aspectos ressaltados nos depoimentos acima podem ser encontrados na elaboração de outros livros digitais: tanto a realização de atividade colaborativa como a seleção prévia de uma linguagem mais próxima ao currículo em estudo. Sobre a integração da atividade ao currículo, foi possível perceber, pelas falas das professoras, que, em alguns casos, a atividade foi inserida dentro de uma proposta mais ampla - como no primeiro depoimento abaixo, em que foi realizada como produção de texto nas aulas de língua portuguesa, ou adicional aos conteúdos trabalhados, sem vínculo direto, como no segundo depoimento.

Produção de texto faz parte do currículo de Língua Portuguesa e existem inúmeras maneiras de se trabalhar esse conteúdo, ora na lousa comum em grupo, sendo que os alunos vão ditando e a professora vai escrevendo, individualmente usando o caderno, organizando um texto conhecido que foi fatiado etc. Mesmo tendo o Wesley como nosso escriba, fazíamos questão de pedir a opinião e a atenção dos alunos na melhor maneira de escrever. Essa atividade com os alunos promove também inclusão digital, mesmo não tendo utilizado os laptops, eles desenharam na lousa digital e digitaram seus nomes na mesma, conheceram e utilizaram vários recursos do PowerPoint. (Profa. MDP).

Foi um projeto a parte, porque achei interessante, pois desenvolve a criatividade dos alunos, além de incentivar o interesse pela leitura. (Profa. SGG).

Neste sentido, ambas as produções foram bem realizadas, embora os

\footnotetext{
${ }^{6}$ Livro digital "O Catador de Pensamentos" (Monica Feth, Athoni Boratynski - Brinquebok) produzido pela profa. Dra. Silvana Lemos, apresentado na oficina dos professores. Disponível em http://issuu.com/sillemos/docs/o_catador_de_pensamentos?e=5921755/2729636. Acesso em 02/12/2013.
} 
laptops UCA não tenham sido utilizados com todo seu potencial. Os alunos puderam ampliar seus conhecimentos direta ou indiretamente relacionados ao currículo em estudo. As professoras se apropriaram dos conhecimentos vivenciados na oficina sobre livro digital, embora infiramos que a sua experiência pedagógica tenha facilitado as questões didáticas da oficina com os alunos, enquanto os elementos mais técnicos ainda prescindiram de apoio do professor especialista em tecnologias. Por outro lado, observamos que realizaram um único projeto de produção de livro digital com toda a classe - ou seja, com mais de 20 alunos, em um grande grupo. Talvez por facilitar a visualização do andamento e a construção coletiva da atividade, todas optaram por utilizar a lousa digital, em conjunto com os laptops UCA ou apenas ela. Para aprofundar o tema, poderiam ser realizados projetos com grupos menores de alunos, com os laptops UCA, para que também este recurso pudesse ser aproveitado e os alunos exercessem maior autonomia na criação dos livros didáticos.

Essas produções foram vistas e analisadas pelos colegas das professoras na oficina seguinte, em setembro de 2014 setembro de 2013, na qual foi dado seguimento ao trabalho de modo a criarem uma versão musicada (áudio, texto e imagens) de uma dessas histórias. Esse processo está descrito e analisado em outro texto (KRUGER-DISSENHA, 2014).

\section{Oficina de fotonovelas}

A segunda experiência descreve a prática dos alunos de um Curso de Licenciatura em Pedagogia de uma Faculdade, localizada na cidade de São Paulo. A disciplina Tecnologia Educacional possui carga horária de 60 horas, ministradas em uma aula semanal ( $2 \mathrm{~h}$ e $30 \mathrm{~min}$ ), para os 90 alunos do curso (em duas turmas). Seu objetivo principal é levar os futuros professores a conhecer as tecnologias, bem como o processo de introdução da informática educacional no Brasil, e apresentar algumas das ferramentas didáticas para suporte ao ensino e a aprendizagem dos conteúdos curriculares com o uso das TDIC. 
A disciplina se apropria do conceito de narrativas digitais a partir dos princípios da Educomunicação ${ }^{7}$, educação e comunicação como intervenção social e ação política, em uma "leitura crítica", como uma produção coletiva que aproxima Educação e Comunicação com uso das TDIC. Os alunos produzem narrativas digitais no formato de fotonovelas com o auxílio do software PowerPoint. As fotonovelas produzidas compõem o acervo da biblioteca virtual da escola por meio de blogs (http://turmapedagogian1a.blogspot.com).

No caso especifico deste estudo, a atenção centrou-se no conteúdo que abordava o tópico das narrativas digitais. O conteúdo foi organizado em duas partes: teórico e prático. Na parte teórica, foram analisados os conceitos e discutidas as características de uma narrativa digital, bem como suas potencialidades e uso em contexto educativo. Para a consecução da parte prática, utilizamos os laboratórios de informática, para que os alunos praticassem os conhecimentos teóricos e construíssem suas narrativas com auxílio da ferramenta PowerPoint.

\subsection{Construção da fotonovela}

No planejamento semestral de 2013, foi discutido o uso e integração das TDIC na produção de Narrativas Digitais, como a fotonovela. A cada semana foi conduzida uma etapa do processo. Na primeira etapa, foram criados e caracterizados os personagens e os cenários. Na caracterização dos personagens foram realizadas reflexões sobre questões estéticas, como cabelo, figurinos, maquiagens e outros. Os participantes também realizaram uma pesquisa de campo na Biblioteca Nacional do Rio de Janeiro com uma mostra de fotonovelas, que os auxiliou a entenderem seu surgimento e principais características ${ }^{8}$. Na segunda etapa, foi planejado o roteiro dos quadros - o Storyboard: o que seria narrado em cada quadro e em cada cena,

\footnotetext{
7 Para definição do conceito, sugere-se acessar Soares et all (2012). Disponível em http://www.pucsp.br/tead/n1a/artigos2/artigo2b.htm. Acesso em 06/abr/2014.

${ }^{8}$ Nesta pesquisa, os participantes constataram que as fotonovelas surgiram na Itália, na década de 1940, com a popularização do cinema e, principalmente, com a popularização dos seus atores. As fotonovelas, naquela época, eram criadas pelos produtores e pelos estúdios cinematográficos para as pessoas que não tinham condições de ir ao cinema. As fotonovelas também envolvem intrigas sentimentais e histórias de superação.
} 
para as fotografias posteriores adequadas a cada quadro. Na terceira e última etapa, a montagem final, foi escrito todo o texto da narrativa. Para a apresentação das histórias das narrativas, foram adicionadas as falas das personagens e do narrador em cada quadro, integrando-as por meio de palavras, imagens e fotografias feitas em diferentes planos pelos alunos no espaço escolar.

\subsection{Apresentação final das fotonovelas}

As duas turmas, com 45 alunos cada, foram organizadas em grupos com, no máximo, oito alunos. Foram produzidas em torno de sete narrativas digitais em cada turma, com temas variados, sendo escolhido um trabalho de cada sala para apresentação neste artigo:

1) "O amor é Cego" (Figura 3): apresenta momentos e personagens que ressaltam a necessidade de humanização relativa ao deficiente visual, a quem é atribuída uma situação de desvantagem em situações corriqueiras.
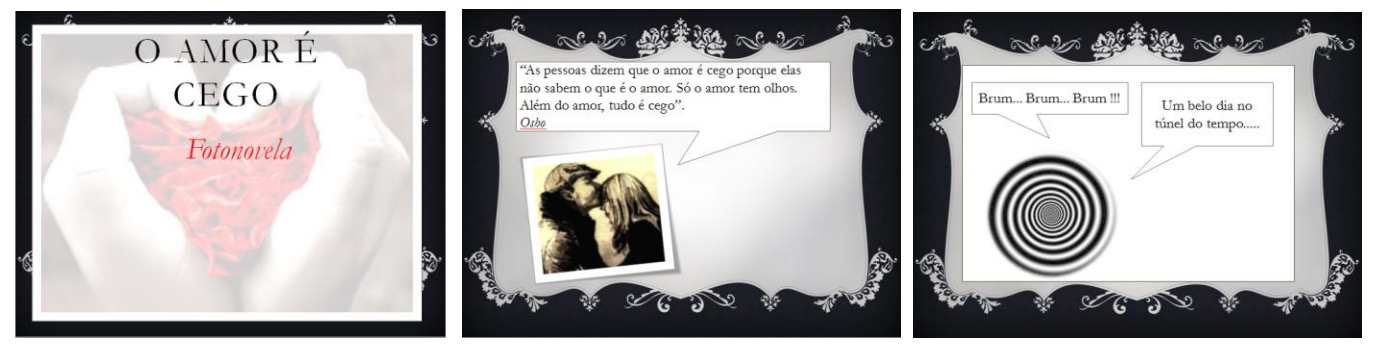

Figura 3: Printscreen das fotonovelas criadas pelos alunos da oficina

2) A segunda história (Figura 4) trata da questão da massificação cultural e a preocupação com a estética imposta pelas mídias, entendida como controle opressivo e dominação das massas. A trama foi relacionada ao drama particular de um dos integrantes do grupo. A narrativa apresenta uma história sobre a luta contra o utilitarismo estético, na concepção de estética em que o consumo de bens culturais pode representar uma forma pela qual as pessoas buscam preservar seus impulsos internos e percepção sensível. 


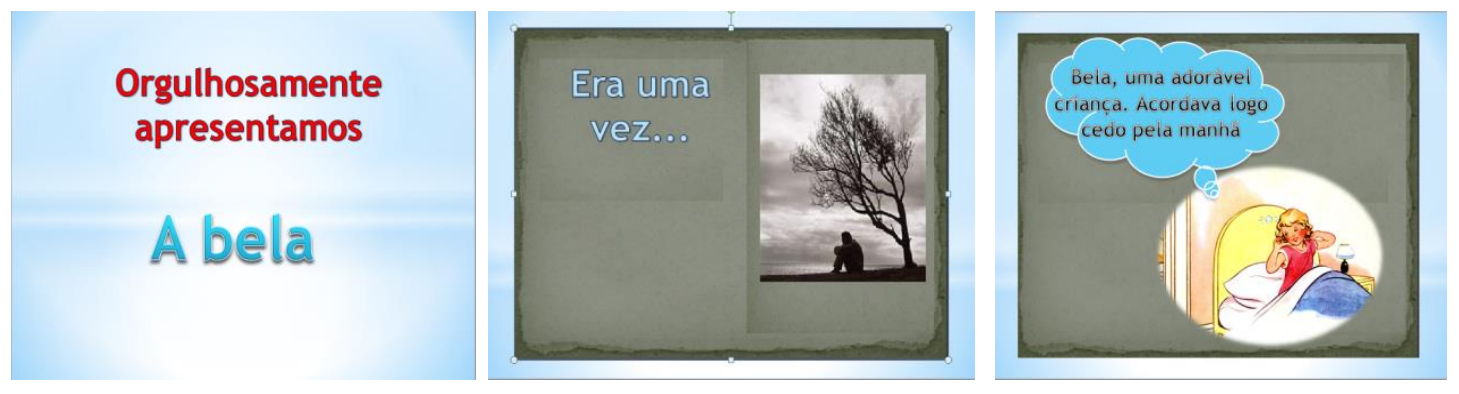

Figura 4: Printscreen de algumas telas de fotonovela criada pelos alunos da oficina

Após as apresentações, os alunos fizeram uma autoavaliação, verificando o seu empenho na proposta, e decidiram disponibilizar as fotonovelas no acervo virtual da biblioteca da instituição.

$\mathrm{Na}$ atividade realizada com as narrativas digitais em formato de fotonovelas, com uso e integração das TDIC, os alunos participantes construíram seu conhecimento sobre o conceito e suas potencialidades educativas, e competências e habilidades no uso da ferramenta (PowerPoint), a qual ultrapassa a mera função de apresentação de informação. Os mesmos mostraram criatividade na produção de recursos didáticos multimídia que poderão ser utilizados em outros contextos de trabalho em que sejam necessários conhecimentos básicos das TDIC. Neste sentido, a disciplina teve uma grande contribuição para o curso de Pedagogia, considerando ter sido recentemente implantada e ministrada pela primeira vez. Isso fez com que os alunos ficassem motivados para fazer uso das tecnologias em contexto pedagógico e, de certa forma, poderá servir como um incentivo para seu uso e investigações futuras.

\section{Conclusões gerais}

As narrativas digitais criadas nas atividades aqui descritas, embora abordadas com recursos tecnológicos diversos e voltadas a públicos diferentes (livro digital: história infantil; fotonovelas: histórias voltadas a adultos), têm como convergência o trabalho com as narrativas, além de terem possibilitado que sujeitos vivenciassem ativamente a construção de seu conhecimento, distribuíssem o conteúdo produzido, e interagissem entre si. 
Nas duas oficinas, realizadas em espaços e tempos diferentes, podemos inferir que ocorreu a integração das TDIC ao currículo em estudo mediante um processo de apropriação tecnológica e pedagógica por parte dos professores. No que diz respeito às competências tecnológicas, observamos algumas dificuldades relacionadas ao uso de softwares em diferentes plataformas, trazendo indagações sobre o perfil do professor do século XXI, que precisa aprender a lidar com diferentes tipos de tecnologias para integrá-las efetivamente ao currículo em estudo. Por outro lado, como exemplo de desenvolvimento das competências pedagógicas, notamos na oficina de livros digitais que, após a apropriação dos recursos tecnológicos, estes foram utilizados em atividades complementares (embora não sempre diretamente vinculadas) ao trabalho dos conteúdos curriculares nas salas de aula, envolvendo língua portuguesa e artes. Segundo Almeida (2010), a integração das TDIC no currículo escolar se dá em diferentes âmbitos:

[...] o currículo construído em ato entre professor e alunos na sala de aula convencional ou no ciberespaço engloba tanto os conhecimentos científicos organizados em materiais didáticos (impressos, audiovisuais, hipermídias) como os elementos simbólicos culturais, os saberes da prática docente, os conhecimentos prévios dos alunos e professores, as práticas sociais de comunicação, as técnicas e os artefatos (p. 69).

Os resultados mostram que ambas as experiências favoreceram a criatividade, o trabalho colaborativo, a pesquisa, a síntese, a organização de ideias e, principalmente, incentivaram o uso das tecnologias em atividades curriculares, podendo ser utilizadas no ensino e na aprendizagem de vários conteúdos em diferentes áreas do currículo.

Nas duas oficinas, a atividade realizada com as narrativas digitais mostrou-se extremamente gratificante. Além dos alunos terem adquirido conhecimento do seu conceito e de suas potencialidades educativas, também adquiriram competências e habilidades no uso das ferramentas (PowerPoint, Internet e ISSUU) que ultrapassam a função básica de apresentação e divulgação de informação e se transformam em recursos para construção de conhecimento. Tanto os professores em formação inicial quanto os atuantes estiveram preparados e abertos para receber as propostas descritas. Os 
professores e alunos em formação que, no início não sabiam buscar informações na internet, localizar imagens, salvá-las, descarregar as fotos da máquina digital, utilizar o software PowerPoint, enviar um e-mail com arquivos anexos, realizavam todas estas tarefas ao final das oficinas. Já os professores em atuação no ensino fundamental não tiveram tantas dificuldades tecnológicas e pedagógicas, provavelmente por já terem participado de oficinas relacionadas ao Projeto UCA por mais de dois anos e devido à sua experiência pedagógica em geral. Cabe observar que, em ambas as oficinas, houve uma reflexão quanto à prática e uma conscientização dos participantes em relação ao potencial do uso das TDIC como apoio e integração ao currículo escolar. Os professores da oficina e da disciplina, enquanto agentes formadores nas duas situações, proveram condições para que os professores participantes, por meio da produção das narrativas digitais, exercessem autonomia para efetivar sua autoria e ampliassem suas perspectivas sobre a integração das tecnologias ao currículo. De modo geral, constatamos uma evolução no aprendizado dos participantes, que surpreenderam frente aos desafios propostos, demostrando sua criatividade na produção de recursos didáticos multimídia que poderão ser utilizados em outros contextos de trabalho em que sejam necessários conhecimentos básicos em TDIC.

Por outro lado, as oficinas demonstraram que ainda é necessário que os professores se apropriem mais das TDIC para sua plena integração ao currículo, utilizando os diferentes recursos (softwares e equipamentos, como os laptops, tablets, lousas digitais, computadores, entre outros) para o trabalho de conteúdos específicos do currículo escolar. Também é pertinente pensar estratégias apropriadas para cada uma das atividades, envolvendo diferentes agrupamentos de alunos conforme os objetivos previstos. Esta diversidade pode ser importante para que se compreenda como ocorrem os processos de construção do conhecimento de modo mais particular, possibilitando que 0 professor oriente os alunos em dificuldades e interesses específicos. Nesse sentido, as orientações do projeto da UNESCO quanto aos "Padrões de Competência em TIC para Professores (ICT-CST)", voltados a "melhorar a prática docente em todas as áreas de trabalho" (UNESCO, 2009, p.05), podem 
apoiar as formações iniciais e continuadas de professores.

Os padrões e recursos no projeto da UNESCO Padrões de Competência em TIC para Professores apresentam diretrizes específicas para o planejamento de programas educacionais e treinamento de professores para o desempenho de seu papel na formação de alunos com habilidades em tecnologia. (ibid., p.01) (...) O projeto de Padrões de Competência em TIC para os Professores também aborda seis componentes do sistema de ensino. É importante observar que os padrões não se limitam na concentração de habilidades de TIC. Pelo contrário. Eles incluem o treinamento em habilidades de TIC como parte de uma abordagem mais ampla à reforma do ensino, que inclui: política, currículo e avaliação, pedagogia, uso da tecnologia, organização e administração da escola e desenvolvimento profissional. (ibid, p.06)

No âmbito da organização e administração, por exemplo, são incluídas no documento propostas para que os professores otimizem a organização da sala de aula no uso das TDIC, como "Identificar os arranjos sociais adequados e inadequados para usar as diversas tecnologias" e "Gerenciar o uso de recursos complementares de TIC, individualmente, e com pequenos grupos de alunos, a fim de não interromper as atividades de ensino em sala". O documento também se refere ao uso dos laboratórios de informática, propondo que os professores aprendam a "Integrar o uso de um laboratório de informática às atividades de ensino em andamento" (p.11). É importante que essa orientação seja voltada à integração destes recursos e espaços ao currículo e à sala de aula, pois muitas escolas ainda possuem apenas os laboratórios de informática e poucas participam dos atuais editais do Programa UCA ou de outras propostas de uso de equipamentos tecnológicos em sala, como tablets e lousas digitais. Ela pode reforçar a necessidade de que o próprio professor de sala de aula desenvolva as atividades curriculares com as TDIC, o que pode ser feito mediante 0 apoio de um professor especialista (quando for o caso), e não o contrário, como ainda ocorre em alguns sistemas de ensino que possuem este profissional em seus quadros. No caso da escola de ensino fundamental aqui citada, por exemplo, a integração e a colaboração entre as professoras de sala de aula e o professor de apoio da área de tecnologias educacionais podem ser consideradas bastante efetivas.

No âmbito pedagógico, por exemplo, os Padrões de Competência em TIC para Professores da UNESCO propõem que os cursos de formação (inicial e 
continuada) de professores desenvolvam habilidades como "Descrever como o ensino didático e as TIC podem ser usadas para apoiar a aquisição, por parte dos alunos, do conhecimento da disciplina escolar", em estratégias que apresentem tanto softwares quanto seu uso em sala de aula; e "Incorporar as atividades apropriadas em TIC aos planos de aula, de modo a ajudar 0 processo de aquisição, pelos alunos, do conhecimento da disciplina escolar", por meio de planejamento de atividades utilizando diferentes tipos de softwares, e que estes planos sejam compartilhados entre os professores (UNESCO, 2009, p.09). Consideramos assim que, na medida em que as formações iniciais e continuadas de professores para a integração das TDIC ao currículo escolar se tornem cada vez mais usuais, também estes profissionais se sentirão mais seguros em realizar atividades que promovam o pleno desenvolvimento dos alunos, possibilitando focar as atividades no conhecimento a ser construído a partir do conteúdo curricular e não apenas nos recursos tecnológicos.

Esperamos que, a partir das experiências aqui relatadas e das decorrentes reflexões, outros professores possam desenvolver trabalhos semelhantes, pois, como verificado, é possível desenvolver várias atividades relacionadas a narrativas digitais com as TDIC, em diferentes contextos.

\section{Referências bibliográficas}

ALMEIDA, M. E. B. A Sala de aula no Século XXI: Inovação e Criticidade. Projeto submetido e aprovado no Edital 001/2010 MEC/CAPES e MCT/CNPq/FINEP, 2010.

ALMEIDA, M. E. B.; VALENTE, J. A. Integração Currículo e Tecnologias e a Produção de Narrativas Digitais. Revista Currículo sem Fronteiras, v. 12, n. 3, p. 57-82, Set/Dez 2012. Disponível em www.curriculosemfronteiras.org. Acesso em 27/fev/2013.

BALDO, A. Gêneros discursivos ou tipologias textuais? Revista Virtual de Estudos da Linguagem - ReVEL. V. 2, n. 2, março de 2004. Disponível em www.revel.inf.br. Acesso em 19/dez/2013.

BAKHTIN, M. Estética da Criação Verbal. São Paulo: Martins Fontes, 1992. 
BONINI, A. Ensino de gêneros textuais: a questão das escolhas teóricas e metodológicas. Trabalhos em Lingüística Aplicada, n. 37, p. 7-23, 2001.

BOTTENTUIT JUNIOR, J. B. Concepção, Avaliação e Dinamização de um Portal Educacional de Web Quests em Língua Portuguesa. Tese de Doutoramento em Ciências da Educação, Área de Conhecimento de Tecnologia Educativa. Braga: Universidade do Minho, Instituto de Educação, 2011.

CARVALHO, G. S. As Histórias Digitais: Narrativas no Século XXI. O Software Movie Maker como Recurso Procedimental para a Construção de Narrações. Dissertação (Mestrado em Educação), 2008.

COUTINHO, C. P. Storytelling as a Strategy for Integrating Technologies into the Curriculum: An Empirical Study with Post-Graduate Teachers. In C. Maddux; D. Gibson\& B. Dodge (Eds.). Research Highlights in Technology and Teacher Education 2010. (pp. 87-97). Chesapeake, VA: SITE, 2010.

DOURADO, S. M.; ODDONE, N. E. A arquitetura do livro digital na plataforma Google: um estudo exploratório. Enc. Bibli: R. Eletr. Bib. Ci. Inf., ISSN 1518-2924, Florianópolis, v. 17, n. 34, p.131-141, maio/ago 2012. Disponvível em https://periodicos.ufsc.br/index.php/eb/article/view/15182924.2012v17n34p131/22612. Acesso 06/abr/2014.

GALVÃO, C. Narrativas em Educação, Ciência \& Educação, v. 11, n.2, 2005. Disponível em http://dx.doi.org/10.1590/s1516-73132005000200013. Acesso em 02/abr/2014.

HASAN, R. Text in the Systemic Funcitonal Model. In: DRESSLER, W. U. Current Trend in Textlinguistics. Berlin, New York: Walter di Gruyter, 1978.

KRUGER-DISSENHA, S. E. A Apropriação Tecnológica e Pedagógica das TICs pelos Sujeitos das Escolas Participantes do Programa UCA: três estudos de caso. Projeto de pesquisa de Pós-doutorado aprovado no Edital 001/2010 MEC/CAPES e MCT/CNPq/FINEP (como parte do Projeto de pesquisa de Almeida, 2010). São Paulo, 2012.

The use of ICT in Brazilian Public Schools: the Re-creation of Stories and Music in a Musical E-book. Congresso Internacional da ISME. Porto Alegre, ISME/ABEM, 2014. No prelo.

PAIVA, V. Narrativas Multimídia de Aprendizagem de Língua Inglesa: um

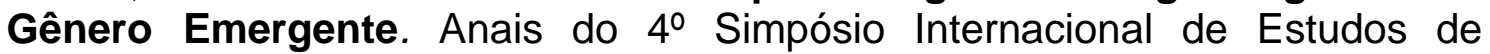
Gêneros Textuais, Tubarão: UNISUL, 2007.

Plano Nacional do Livro Didático (PNLD). Edital de Convocação 01/2013 CGPLI, Ensino Médio 2015. Disponível em http://www.fnde.gov.br/programas/livro-didatico/livro-didatico-editais/item/4032pnld-2015. Acesso em 06/abr/2014. 
SILVA, A. J. A Internet no Ensino das Ciências Físico-Química. Dissertação de Mestrado em Ensino da Física. Coimbra: Universidade de Coimbra, 1997.

SWALES, J. M. Genre Analysis: English in Academic and Research Settings. Cambridge: Cambridge University Press, 1990.

UNESCO. Padrões de competência em TIC para Professores. Diretrizes de implementação. Versão 1.0. Tradução DAVID, C. B. Revisão Técnica:

BASTOS, M. I,; Revisão: REIS, R. L.; SAWAYA, J. UNESCO, 2009. Disponível em http://www.unesco.org/en/competency-standards-teachers. Acesso em 09/abr/2014. 
Artigo recebido em: 20/12/2013

Artigo avaliado em: 15/04/2014

\section{Sobre as autoras:}

Cristiane A. Neri FIDELIX: Mestranda em Educação: Currículo pela Pontifícia Universidade Católica - SP.

Susana Ester KRUGER-DISSENHA: Pós-doutoranda em Educação: Currículo na Pontifícia Universidade Católica - SP. 